Proceedings

\title{
A Regional Sensitivity Analysis of a Multi-Variable Hydrological Model: A Case Study of a Greek Catchment ${ }^{\dagger}$
}

\author{
Panagiota Venetsanou 1,*, Christina Anagnostopoulou ${ }^{2}$, Athanasios Loukas ${ }^{3}$ and \\ Konstantinos Voudouris ${ }^{1}$ \\ 1 Laboratory of Engineering Geology and Hydrogeology, Department of Geology, Aristotle University of \\ Thessaloniki, 54124 Thessaloniki, Greece; kvoudour@geo.auth.gr \\ 2 Laboratory of Meteorology and Climatology, Department of Geology, Aristotle University of Thessaloniki, \\ 54124 Thessaloniki, Greece; chanag@geo.auth.gr \\ 3 Department of Rural and Surveying Engineering, Aristotle University of Thessaloniki, 54124 Thessaloniki, \\ Greece; agloukas@topo.auth.gr \\ * Correspondence: pvenetsn@geo.auth.gr \\ † Presented at the 3rd International Electronic Conference on Water Sciences, 15-30 November 2018; \\ Available online: https://ecws-3.sciforum.net. \\ Published: 15 November 2018
}

\begin{abstract}
The importance of climate data in hydrological process simulation is widely recognized. Evaluation of the hydrological budget response to climate variability is required, especially in water resource management. The present paper illustrates a case study of a sensitivity analysis for the hydrological model SWAT (Soil and Water Assessment Tool) using climate data from the Havrias river basin in northern Greece. The ERA-Interim reanalysis daily climate data were used as input data to drive the SWAT model. The SWAT model was calibrated for the period from 1981 to 2000. The sensitivity of the hydrological parameters to the alteration of the climate data was analyzed by using eleven hypothetical scenarios. These scenarios regard different combinations of temperature, wind speed, precipitation, and relative humidity. The results show that the changes of precipitation temperature and relative humidity have a significant influence in evapotranspiration and percolation (and consequently recharge) in the study region. On the contrary, the wind speed negligibly affects the hydrological components. Overall, the Havrias river basin hydrological budget is sensitive to shifts in climate data and the utilization of reliable and accurate climate models outputs is necessary in order for water managers to be able to build scenarios providing sustainability against potential future climate changeimpacts.
\end{abstract}

Keywords: SWAT software; Havrias River Basin; climate variability; water budget components

PACS: J0101

\section{Introduction}

Numerous multi-variable hydrological models have been widely implemented to comprehend hydrological processes and establish the water balance. The credibility and effectiveness of these models are mostly dependent on their inputs, especially the climate data. The comprehension of the hydrological budget components' response to climate variability has become more and more fundamental. Based on the Intergovernmental Panel on Climate Change [1], the climate change effects on water resources are unambiguous. In several scientific studies, hydrological models have been used in order to assess the hydrological cycle response under different climate scenarios [2-4]. 
Song et al. [5] presented a review of the sensitivity analysis in hydrological simulation, underlining its importance and appropriate role.

The objective of this paper is to conduct a sensitivity analysis of the hydrological budget components of a watershed in response to variations in climate parameters. The Soil and Assessment Water Tool (SWAT) was used for the modeling of the watershed. The SWAT hydrological model is a suitable and useful tool for watershed process simulations, such as those relating to the water balance and quality, crop growth, climate change, and land management practices. The SWAT application was conducted in the Havrias river basin, which is situated in northern Greece. The Havrias river basin was selected as the case study, because it is an agricultural and ungauged watershed and can be considered a representative watershed of the Greek region. The ultimate scope of this paper is to comprehend which of the climate parameters most influence the model's performance.

\section{Materials and Methods}

\subsection{Study Area}

The Havrias river basin is one of the most significant watersheds of Halkidiki in northern Greece. The basin drains into the Kassandra Gulf. Its elevation varies between $0 \mathrm{~m}$ and $1090 \mathrm{~m}$, covering an extent of $472 \mathrm{~km}^{2}$, based on GIS analysis (Figure 1). The mean slope of the watershed is about $22 \%$. The Mediterranean climate CSa, according to the Köppen classification [6], is identified in the research area. The agricultural land represents approximately $33 \%$ of the total area. The major crops are the olive groves. Broad-leaved, coniferous, and mixed forests occupy the northern part of the watershed. Geologically, the coastal part consists of alluvial deposits, lacustrine and lagoon sediments, red clay, and basic conglomerates series. Metasedimentary rocks, gneiss, phyllite, recrystallized limestone, gabbro, pyroxenites, and dounites are encountered in the rest of the basin. The main aquifer systems are developed within alluvial deposits (porous aquifer) and limestones (karstic aquifer). Water needs for domestic and irrigation use are mainly covered by the exploitation of the aforementioned aquifers through numerous boreholes and wells.

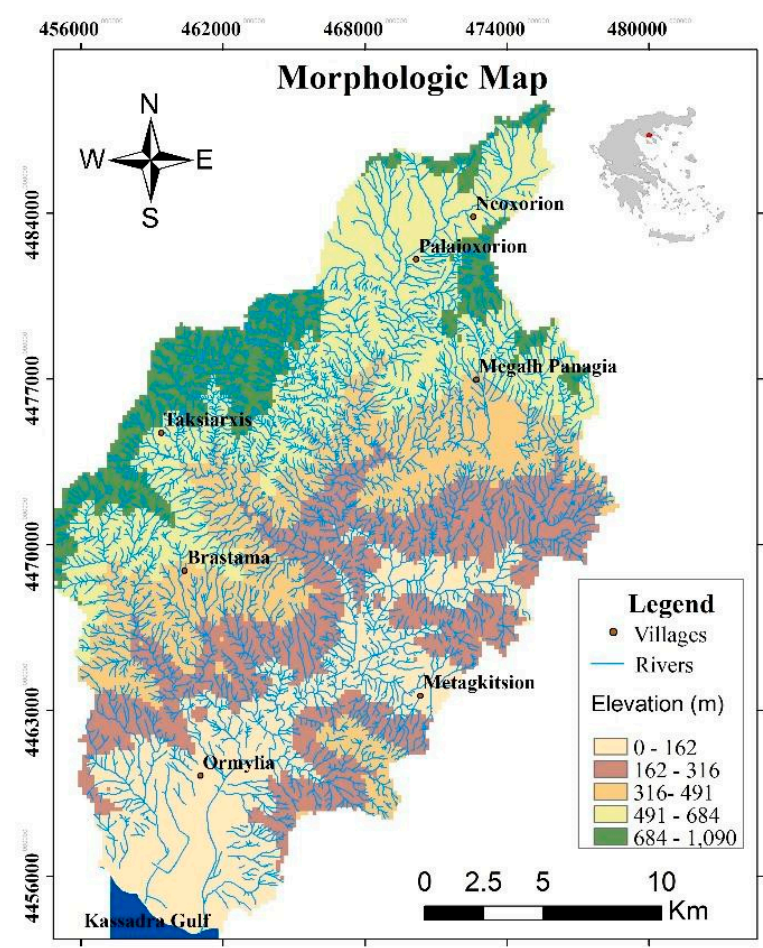

Figure 1. The morphological map of the Havrias river basin. 


\subsection{SWAT Model}

\subsubsection{Description of the SWAT Model}

The Soil and Water Assessment Tool (SWAT) is a watershed-scale hydrological model $[7,8]$ which was developed by the United States Department of Agriculture-Agricultural Research Service (USDA-ARS) (Arnold et al., 1998). It is a semi-distributed and physically-based model, running on a daily time step. Its task is to assess the impact of land and agricultural management practices on water, sediment, and agricultural chemical yields. In SWAT, any watershed is separated into subwatersheds based on the topography and the drainage network. Then, each sub-watershed is further divided into smaller units, which are called hydrologic response units (HRUs). The HRU can be determined as an area within a sub-watershed with the same land use classification, soil properties, slope characteristics, and management combinations. The hydrological process is described by the water balance equation:

$$
S W_{t}=S W_{o}+\sum_{i=1}^{t}\left(R-Q_{\text {surf }}-E T-P-Q R\right)
$$

where

$S W_{t}=$ the final soil water content $(\mathrm{mm}), S W_{o}=$ the initial soil soil water content $(\mathrm{mm}), R=$ the daily precipitation $(\mathrm{mm}), Q_{\text {surf }}=$ the daily runoff $(\mathrm{mm}), \mathrm{ET}=$ the daily evapotranspiration $(\mathrm{mm}), P=$ the daily percolation $(\mathrm{mm})$, and $Q R=$ the groundwater flow per day

A detailed description of the SWAT model is demonstrated by Arnold et al. [9].

\subsubsection{Data}

A variety of data, such as morphological, climate, land use, and soil data, is required for SWAT implementation. A Digital Elevation Model (DEM) with a spatial resolution of $5 \mathrm{~m}$ was used in order to delineate the watershed. The topographical data of the study area were provided by the National Cadastre and Mapping Agency S.A. of Greece. The land use of the study area was derived from the Corine Land Cover 2012 (https://land.copernicus.eu/pan-european/corine-land-cover/clc-2012). The results of the laboratory soil tests, which took place in the Laboratory of Engineering Geology \& Hydrogeology of Aristotle University in Thessaloniki, were taken into consideration in order to create the soil map of the study area.

Daily precipitation, maximum and minimum air temperature, solar radiation, wind speed, and relative humidity data are demanded as SWAT input climate data. In this study, the ERA-Interim reanalysis data with a spatial resolution of $12.5 \mathrm{~km}$, which have been made publicly available by the European Centre for Medium-Range Weather Forecasts (ECMWF) (http://apps.ecmwf.int/datasets/data/ interim-full-daily/levtype=sfc), were used to drive the SWAT model. In the framework of this paper, the ERA-Interim climate data cover the period from 1981 to 2000.

\subsubsection{Model Set Up}

The simulation of the Havrias river basin was conducted by using the ArcSWAT interface for SWAT2012. The Havrias river basin was divided into 23 sub-basins after the watershed delineation. The HRU definition was carried out by using the land use, soil, and slope data. The land cover and the soil data were reclassified based on the SWAT model's specifications. Five slope classes were defined for the HRU classification. A threshold of $0 \%-0 \%-0 \%$ was set up for the land use, soil type, and slope, respectively. Overall, 309 HRUs were created.

The Penman-Monteith method was implemented so as to estimate the potential evapotranspiration (PET). The surface runoff was computed by using the Soil Conservation Service's curve number (CN2) method. The SWAT model was initially run for the period from 1981 to 2000.

The calibration was accomplished by using the trial-and-error procedure.

The sensitivity analysis of the hydrological budget components regarding variation of the climate parameters was carried out by using eleven hypothetical scenarios. Table 1 illustrates these 
scenarios, which include different combinations of temperature, precipitation, wind speed, and relative humidity. The land use remained stable during the simulation of the hypothetical scenarios.

Table 1. The hypothetical climate scenarios.

\begin{tabular}{ccccc}
\hline Scenario & $\begin{array}{c}\text { Temperature } \\
\left({ }^{\circ} \mathbf{C}\right)\end{array}$ & $\begin{array}{c}\text { Precipitation } \\
(\mathbf{\%})\end{array}$ & $\begin{array}{c}\text { Wind Speed } \\
\mathbf{( \% )}\end{array}$ & $\begin{array}{c}\text { Relative Humidity } \\
\mathbf{( \% )}\end{array}$ \\
\hline 1 & +1 & 0 & 0 & 0 \\
2 & +2.5 & 0 & 0 & 0 \\
3 & 0 & -5 & 0 & 0 \\
4 & 0 & -10 & 0 & 0 \\
5 & +2.5 & 0 & +50 & 0 \\
6 & +2.5 & -5 & +50 & 0 \\
7 & +2.5 & -5 & +50 & -25 \\
8 & +2.5 & +5 & +50 & +10 \\
9 & 0 & +5 & 0 & 0 \\
10 & 0 & +5 & 0 & +5 \\
11 & 0 & 0 & +50 & 0 \\
\hline
\end{tabular}

\section{Results}

\subsection{Hydrological Bugdet Componets Simulation}

Based on the SWAT simulation results regarding the period from 1981 to 2000, the evapotranspiration was calculated and found to be equal to $309.6 \mathrm{~mm}$, representing about $60 \%$ of the mean annual precipitation $(520.1 \mathrm{~mm}$ ) of the Havrias river basin. The potential evapotranspiration was estimated to be equal to $949 \mathrm{~mm}$. Percolation to the shallow aquifer was estimated to be equal to $100.64 \mathrm{~mm}$ and the recharge to the deep aquifer was equal to $5 \mathrm{~mm}$. The surface runoff was computed at $59.51 \mathrm{~mm}$. Figure 2 comprehensively depicts the hydrological procedures of the Havrias river basin.

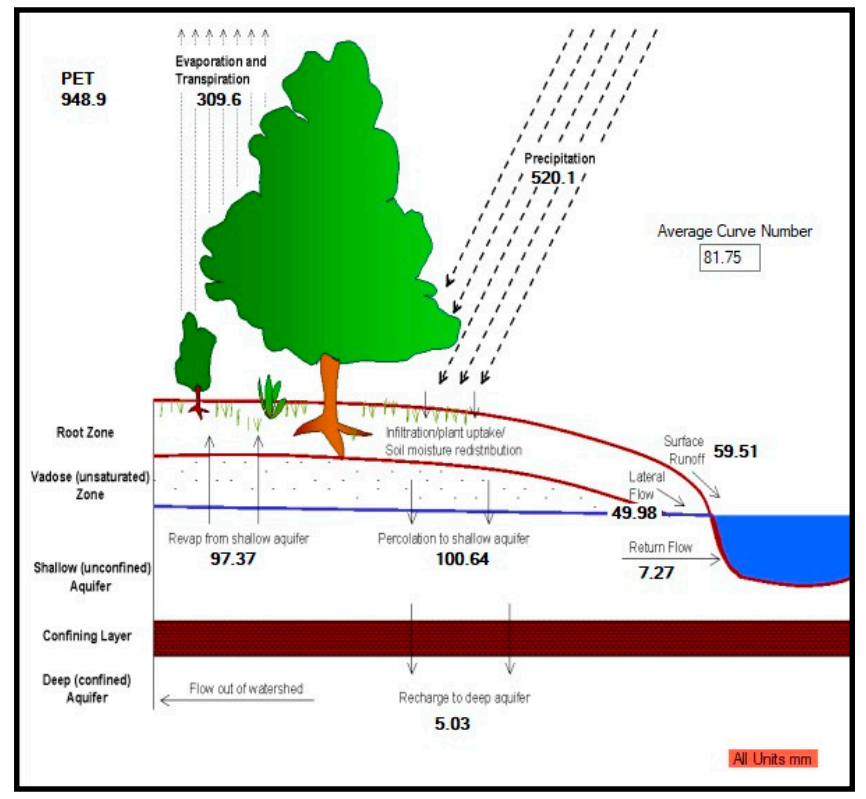

Figure 2. The hydrological procedures of the Havrias river basin for the period 1981-2000.

\subsection{Hydrological Budget Components Simulation Under Different Hypothetical Climate Scenarios}

Table 2 demonstrates the SWAT simulation results of the water budget under different scenarios. The following results can be drawn from the Swat simulation of the Havrias river basin under the hypothetical climate scenarios: 
- The temperature increase of $2.5{ }^{\circ} \mathrm{C}$ (Scenario 2) resulted in increases of $8 \%$ and $1.4 \%$ in potential evapotranspiration and evapotranspiration, respectively. On the contrary, percolation to the shallow aquifer and recharge to the deep aquifer were decreased by $9.3 \%$.

- Reducing and increasing the precipitation reduced and increased all the hydrological components, respectively. No changes were observed in the potential evapotranspiration.

- Increasing only the wind speed (Scenario 11) resulted in a slight decrease in evapotranspiration, percolation, and consequently in recharge.

- The largest increases of evapotranspiration and decreases of runoff and percolation were obtained when all the climate parameters (temperature, precipitation, wind speed, relative humidity) were changed.

- Scenario 7 showed an augment of $59 \%$ and $13 \%$ in potential evapotranspiration and evapotranspiration, respectively, whereas a decrease of $50 \%$ and $11 \%$ in percolation and hence in recharge to the deep aquifer and in surface runoff, accordingly.

Table 2. The SWAT simulated hydrological budget components under the different hypothetical climate scenarios.

\begin{tabular}{|c|c|c|c|c|}
\hline Scenario & $\begin{array}{l}\text { Potential Evapotranspiration } \\
\text { ((mm) }\end{array}$ & $\begin{array}{c}\text { Evapotranspiratio } \\
\mathbf{n} \\
(\mathrm{mm})\end{array}$ & $\begin{array}{c}\text { Percolatio } \\
\mathrm{n} \\
(\mathrm{mm})\end{array}$ & $\begin{array}{l}\text { Surface Runoff } \\
\text { (mm) }\end{array}$ \\
\hline $1981-2000$ & 949 & 309.6 & 106.6 & 59.5 \\
\hline 1 & 979 & 311.3 & 98.6 & 60.2 \\
\hline 2 & 1024.5 & 314.0 & 96.2 & 60.3 \\
\hline 3 & 949.0 & 299.1 & 93.9 & 53.2 \\
\hline 4 & 949.0 & 289.4 & 86.3 & 47.7 \\
\hline 5 & 1219.3 & 332.1 & 84.4 & 56.5 \\
\hline 6 & 1219.3 & 321.9 & 77.6 & 50.3 \\
\hline 7 & 1515.6 & 359.4 & 52.9 & 41.9 \\
\hline 8 & 1143.9 & 350.2 & 54.6 & 61.5 \\
\hline 9 & 949.0 & 316.9 & 108.7 & 66.9 \\
\hline 10 & 900.8 & 321.1 & 106.0 & 66.0 \\
\hline 11 & 949 & 308.2 & 101.2 & 59.8 \\
\hline
\end{tabular}

\section{Discussion and Conclusions}

A regional sensitivity analysis of the hydrological budget components of the Havrias river basin with regards to variations of the climate parameters was performed in this study. The sensitivity analysis showed that the Havrias river basin is vulnerable to variability of the climate parameters. Based on the SWAT simulation results, the temperature, precipitation, and relative humidity highly influence the hydrological budget components of the study area. In contrast, the wind speed has a negligible role in hydrological processes. In accordance with the author's findings, Ficklin et al. (2009) showed that the hydrological system of a highly agricultural watershed is sensitive to climate variability. According to their results, the changes in temperature highly influence the hydrological components.

This paper presents preliminary research on the assessment of the sensitivity of the hydrological components to potential future climate change, laying the foundation for using the climate models outputs so as to quantify the climate change impacts on water resources. The coupling of reliable climate and hydrological models is essential in order for water managers to be able to build scenarios providing sustainability against the anticipated climate change.

Author Contributions: P.V. collected and evaluated the data, and wrote the paper. C.A. conceived the idea and evaluated the climate data. A.L. contributed to the application of the SWAT model. K.V. coordinated and supervised the project. 
Acknowledgments: This research has been financially supported by the General Secretariat for Research and Technology (GSRT) and the Hellenic Foundation for Research and Innovation (HFRI) (Scholarship Code: 174, 95543).

Conflicts of Interest: The authors declare no conflict of interest.

\section{Abbreviations}

The following abbreviation is used in this manuscript:

\section{SWAT Soil and Water Assessment Tool}

\section{References}

1. IPCC Climate Change 2013. Synthesis Report. 2013. Available online: https://www.ipcc.ch/report/ar5/wg1/ (accessed on 10 October 2018).

2. Ficklin, D.L.; Luo, Y.; Luedeling, E.; Zhang, M. Climate change sensitivity assessment of a highly agricultural watershed using SWAT. J. Hydrol. 2009, 374, 16-29, doi:10.1016/j.hydrol.2009.05.016.

3. Fadil, A.; Rhinane, H.; Kaoukaya, Y.K.; Bachir O.A. Hydrologic Modeling of the Bouregreg Watershed (Morocco) Using GIS and SWAT Model. J. Geogr. Inf. Syst. 2011, 3, 279-289, doi:10.4236/jgis.2011.34024.

4. Gneneyougo, E.S, Affoué, B.Y.; Yao, M.K.; Tié, A.G.B.; Climate Change and Its Impacts on Water Resources in the Bandama Basin, Côte D'ivoire. Hydrology 2017, 4, 18, doi:10.3390/hydrology4010018.

5. Song, X.; Zhang, J.; Zhan, C.; Xuan, Y.; Ye, M.; Xu, C. Global sensitivity analysis in hydrological modeling: Review of concepts, methods, theoretical framework, and applications. J. Hydrol. 2015, 523, 739-757, doi:10.1016/j.hydrol.2015.02.013.

6. Köppen, W. Classification of climates and world patterns. In An Introduction to Climate; Trewartha, G.T., Ed.; McGraw-Hill: New York, NY, USA, 1954; pp. 225-226.

7. Arnold, J.G.; Srinivasan, R.; Muttiath, R.S.; Williams J.R. Large area hydrologic modelling and assessment part I: Model development. J. Am. Water Resour. Assoc. 1998, 34, 73-89.

8. Nietsch, S.L.; Arnold, J. D.; Kiniry, J.R.; Williams, J.R.; King, K.W. Soil and Water Assessment Tool Theoretical Documentation; Version 2005; Texas Water Resource Institute: College Station, TX, USA, 2005.

9. Arnold, J.G; Moriasi, D.N.; Gassman, P.; Abbaspour K.C.; White M.J.; Srinivasan R.; Harnal, R.D.; van Griensven, A.; van Liew, M.W.; Kanman, N.; et al. SWAT: Model use, calibration and validation. ASABE 2012, 55, 1491-1508.

(C) 2018 by the authors. Licensee MDPI, Basel, Switzerland. This article is an open access article distributed under the terms and conditions of the Creative Commons Attribution (CC BY) license (http://creativecommons.org/licenses/by/4.0/). 